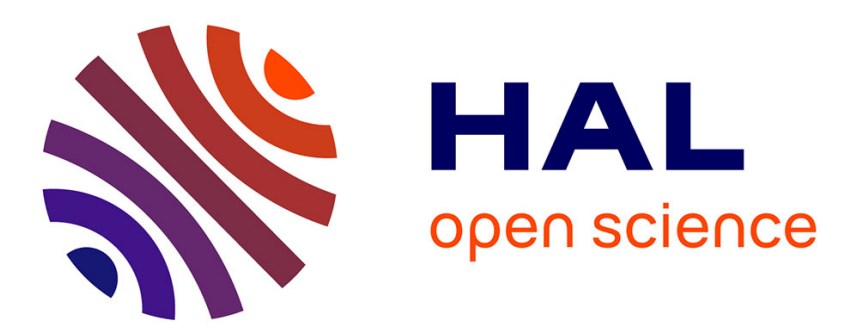

\title{
A Parametric Spectral Estimator for Faults Detection in Induction Machines
}

El Houssin El Bouchikhi, Vincent V. Choqueuse, Mohamed Benbouzid

\section{To cite this version:}

El Houssin El Bouchikhi, Vincent V. Choqueuse, Mohamed Benbouzid. A Parametric Spectral Estimator for Faults Detection in Induction Machines. IECON 2013, Nov 2013, Vienne, Austria. pp.7358

- 7363, 10.1109/IECON.2013.6700357 . hal-00926738

\section{HAL Id: hal-00926738 \\ https://hal.science/hal-00926738}

Submitted on 14 Jan 2014

HAL is a multi-disciplinary open access archive for the deposit and dissemination of scientific research documents, whether they are published or not. The documents may come from teaching and research institutions in France or abroad, or from public or private research centers.
L'archive ouverte pluridisciplinaire HAL, est destinée au dépôt et à la diffusion de documents scientifiques de niveau recherche, publiés ou non, émanant des établissements d'enseignement et de recherche français ou étrangers, des laboratoires publics ou privés. 


\title{
A Parametric Spectral Estimator for Faults Detection in Induction Machines
}

\author{
El Houssin El Bouchikhi ${ }^{1}$, Vincent Choqueuse ${ }^{1}$, and M.E.H. Benbouzid ${ }^{1}$ \\ ${ }^{1}$ University of Brest, EA 4325 LBMS, Rue de Kergoat, CS 93837, 29238 Brest Cedex 03, France
}

\begin{abstract}
Current spectrum analysis is a proven technique for fault diagnosis in electrical machines. Current spectral estimation is usually performed using classical techniques such as periodogram (FFT) or its extensions. However, these techniques have several drawbacks since their frequency resolution is limited and additional post-processing algorithms are required to extract a relevant fault detection criterion. Therefore, this paper proposes a new parametric spectral estimator that fully exploits the faults sensitive frequencies. The proposed technique is based on the maximum likelihood estimator and offers high-resolution capabilities. Based on this approach, a fault criterion is derived for detecting several fault types.

The proposed faults detection technique is assessed using simulations, issued from a coupled electromagnetic circuits approach-based simulation tool. It is afterwards validated using experiments on a $0.75-\mathrm{kW}$ induction machine test bed for the particular case of bearing faults.
\end{abstract}

Index Terms-Induction machine, faults detection, bearing faults, stator current, parametric spectral estimation.

\section{INTRODUCTION}

Condition monitoring is of high concern in industrial applications since it minimizes the downtime and improves the reliability, availability, safety and productivity of electrical drives. For electrical motors and generators, fault detection is usually performed by vibration monitoring, temperature measurements, oil monitoring, flux monitoring or current analysis. Among these various techniques, current analysis has several advantages since it is a noninvasive technique that avoids the use of extra sensors since the stator currents are usually available and inexpensive to measure [1]-[4].

Many studies have shown that fault monitoring could be performed by supervising the current spectrum. In particular, it has been demonstrated that faults introduce additional spectral components in the stator current around the supply frequency [3], [4]. For a faulty machine, the frequency location of these components is given by $f_{k}(\Omega)$, where $f_{k}$ corresponds to the $k^{\text {th }}$ component $(k \in \mathbb{Z})$, and $\Omega$ is a set of parameters that must be estimated in order to determine the induction machine health condition. These frequencies are associated with several mechanical and/or electrical faults such as air-gap eccentricity, bearing failures or broken rotor bars. Traditional current-based techniques for fault detection monitor the stator current spectrum and, more precisely, the fault characteristic frequencies [5]. In steady-state conditions, techniques based on conventional power spectral density (PSD) estimators have been employed. These techniques can be classified into two categories: non-parametric and parametric methods.

Non-parametric methods include the periodogram, which is usually implemented using Fast Fourier Transform (FFT), and its extensions. The classical periodogram has been applied for fault detection in [3], [4]. The main drawback of this technique relies on its performance. The so-called Zoom-FFT (ZFFT) technique [6], [7] has been introduced to improve the frequency accuracy in a specified frequency range without increasing the computational complexity. Nevertheless, the periodogram and its extensions suffer from a low frequency resolution, which is defined as the ability to distinguish two closely spaced frequency components [8]. Parametric methods can be employed to improve the frequency resolution. These techniques are generally called high-resolution methods and include two sub-classes: the linear prediction methods and the subspace techniques. The linear prediction class contains several algorithms like the Prony and Pisarenko methods. The use of these methods for fault detection in electrical drives has been investigated in [9] and [10]. The subspace class includes the MUSIC and ESPRIT approaches. Applications for induction machine faults diagnosis are available in [11]-[14]. However, these techniques are computationally demanding and statistically suboptimal.

In this paper, we propose a parametric PSD estimator based on the maximum likelihood estimator (MLE). The MLE is asymptotically optimal PSD estimator [15]. In the case of induction machine fault detection, we demonstrate that the MLE is computationally efficient since it leads to a 2-D optimization problem that is easy to implement. Besides, an efficient implementation of the MLE requires the knowledge of frequency components numbers which is a model order estimation problem. In order to estimate the model order, we propose to combine the MLE with an order-dependent penalty term based on information criteria rules [16]. It must be emphasized that the sidebands number $(2 \times L)$ estimation is of great interest since it contribute to inform us about the fault existence. Moreover, if the order is not estimated (chosen) correctly, the fault characteristic frequency may erroneously be estimated at, for example, half or double of the true value. First, the model order and the PSD are estimated by using the MLE combined with information theoretic criteria. Then, a simple fault criterion is computed from the amplitude estimate of the fault characteristic frequencies. 


\section{STATOR CURRENT SIGNAL MODEL}

\section{A. Faults Effect on Stator Current Spectrum}

The induction machine is subjected to various failures that affect mainly three components : the stator, the rotor and/or the bearings. Recent paper dealing with induction machine faults distribution [17] have shown that bearings (69\%), stator windings $(21 \%)$, rotor $(7 \%)$, and shaft/coupling $(3 \%)$ are the most failing components. Most of the recent researches on induction machine faults detection has been directed toward electrical monitoring with emphasis on stator current supervision. In particular, the current spectrum is analysed to extract the frequency components introduced by the fault. A summary of stator current induction machine faults related frequencies are presented in Table 1.

Table 1. Induction machine faults signatures [3], [4].

\begin{tabular}{|c||c|c|}
\hline $\begin{array}{c}\text { Induction } \\
\text { machine state }\end{array}$ & $\begin{array}{c}\text { Frequency } \\
\text { Signature }\end{array}$ & Parameters \\
\hline $\begin{array}{c}\text { Bearing } \\
\text { Damage }\end{array}$ & $\left|f_{s} \pm k f_{o}\right|$ & $k=1,2,3, \ldots$ \\
\hline $\begin{array}{c}\text { Broken } \\
\text { Rotor Bars }\end{array}$ & $f_{s}\left[k\left(\frac{1-s}{p}\right) \pm s\right]$ & $\frac{k}{p}=1,5,7, \ldots$ \\
\hline $\begin{array}{c}\text { Air Gap } \\
\text { Eccentricity }\end{array}$ & $f_{s}\left[1 \pm k\left(\frac{1-s}{p}\right)\right]$ & $k=1,2,3, \ldots$ \\
\hline $\begin{array}{c}\text { Load } \\
\text { Oscillation }\end{array}$ & $f_{s}\left[1 \pm k\left(\frac{1-s}{p}\right)\right]$ & $k=1,2,3, \ldots$ \\
\hline
\end{tabular}

Where $s$ is the per unit slip, $f_{o}$ corresponds to one of the characteristic vibration frequencies which depends on the bearing dimensions, and $p$ is the number of pole pairs.

The frequencies given by Table 1 are used in the faulty induction machine stator current model described in the following section. When a fault occurs, the amplitude of these frequencies increases and reveals abnormal operating conditions.

\section{B. Induction Machine Stator Current Signal Model}

Based on the faults signature described on Table 1, the stator-current samples $x[n]$ can be expressed as

$$
x[n]=\sum_{k=-L}^{L} a_{k} \cos \left(2 \pi f_{k}(\Omega) \times\left(\frac{n}{F_{s}}\right)+\phi_{k}\right)+b[n]
$$

The observation noise $\mathbf{b}[n]$ is assumed to be zero-mean white Gaussian distributed with variance $\sigma^{2}$ i.e. $b[n] \sim$ $\mathscr{N}\left(0, \sigma^{2}\right)$. Symbols $f_{k}(\Omega), a_{k}$ and $\phi_{k}$ correspond to the frequency, the amplitude and the phase of the $k^{t h}$ frequency component, respectively. $\Omega$ is a set of parameters to be estimated in order to get the signal power spectral density. Symbol $F_{S}$ corresponds to the sampling rate.

The theoretical PSD of $x[n]$ is given by Fig. 1 [8]. In practice, the PSD is unknown, and must be estimated from

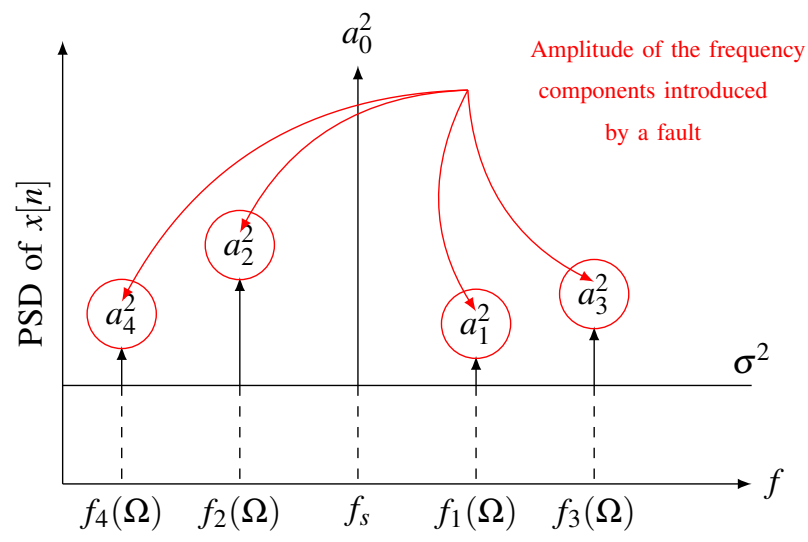

Fig. 1. Theoretical PSD for $L=2$ [8].

$N$ samples. Using a matrix notation, $x[n](n=0, \cdots, N-1)$ can be expressed as

$$
\mathbf{x}=\mathbf{A}(\Omega) \mathbf{v}+\mathbf{b}
$$

where:

- $\mathbf{x}=[x[0], \cdots, x[N-1]]^{T}$ is a $N \times 1$ column vector containing the stator current samples,

- $\mathbf{b}=[b[0], \cdots, b[N-1]]^{T}$ is a $N \times 1$ column vector containing the noise samples,

- $\mathbf{v}$ is a $2(2 L+1) \times 1$ column vector containing the amplitudes and phases of the characteristic fault frequencies. This vector is given by

$$
\begin{aligned}
\mathbf{v}=\left[a_{-L} \cos \left(\phi_{-L}\right) \ldots a_{L} \cos \left(\phi_{L}\right),\right. \\
\left.\quad-a_{-L} \sin \left(\phi_{-L}\right) \ldots-a_{L} \sin \left(\phi_{L}\right)\right]^{T}
\end{aligned}
$$

- $\mathbf{A}(\Omega)$ is a $N \times 2(2 L+1)$ matrix given by

$$
\mathbf{A}(\Omega)=\left[\mathbf{z}_{-L} \ldots \mathbf{z}_{L}, \mathbf{y}_{-L} \ldots \mathbf{y}_{L}\right]
$$

where

$$
\begin{aligned}
& \mathbf{z}_{k}=\left[1 \cos \left(2 \pi f_{k}(\Omega) \times \frac{1}{F_{s}}\right) \ldots \cos \left(2 \pi f_{k}(\Omega) \times \frac{N-1}{F_{s}}\right)\right]^{T} \\
& \mathbf{y}_{k}=\left[0 \sin \left(2 \pi f_{k}(\Omega) \times \frac{1}{F_{s}}\right) \ldots \sin \left(2 \pi f_{k}(\Omega) \times \frac{N-1}{F_{s}}\right)\right]^{T}
\end{aligned}
$$

We propose a parametric estimator that exploits the signal model in (2). Hence, the computation of the current spectrum from stator current samples $\mathbf{x}$ is treated as a statistical estimation problem.

\section{PARAMETRIC PSD ESTIMATION}

In this section, we present a maximum likelihood estimator for PSD estimation based on the signal model given by (2). Then, the MLE is extended to take into account the estimation of the model order. Finally, a fault detection criterion is computed based on these estimates. 


\section{A. Proposed Estimator}

The MLE is used in order to estimate $\mathbf{v}$ and $\Omega$. Then a penalty term is applied to the MLE cost function in order to estimate the model order i.e. $L$.

1) Estimate of $v$ and $\Omega$ : The ML estimator of $\mathbf{v}$, and $\Omega$ is given by

$$
\{\widehat{\mathbf{v}}, \widehat{\Omega}\}=\arg \max _{\mathbf{v}, \Omega} \log (p(\mathbf{x} ; \mathbf{v}, \Omega))
$$

where $p(\mathbf{x} ; \mathbf{v}, \Omega)$ is the probability density function (pdf) of $\mathbf{x}$ which is given by

$$
\begin{gathered}
p(\mathbf{x} ; \mathbf{v}, \Omega)=\frac{1}{\left(2 \pi \sigma^{2}\right)^{\frac{N}{2}}} \\
\times \quad \exp \left[-\frac{1}{2 \sigma^{2}}(\mathbf{x}-\mathbf{A}(\Omega) \mathbf{v})^{T}(\mathbf{x}-\mathbf{A}(\Omega) \mathbf{v})\right]
\end{gathered}
$$

where $(.)^{T}$ denotes the matrix transpose. The ML estimates of $\Omega$ and $\mathbf{v}$ are obtained by maximizing the pdf with respect to the unknown parameters. The maximization in (6) is equivalent to the minimization of the following cost function [18]:

$$
\mathscr{L}(\mathbf{x} ; \mathbf{v}, \Omega)=(\mathbf{x}-\mathbf{A}(\Omega) \mathbf{v})^{T}(\mathbf{x}-\mathbf{A}(\Omega) \mathbf{v})
$$

Differentiating $\mathscr{L}(\mathbf{x} ; \mathbf{v}, \Omega)$ with respect to $\mathbf{v}$ and setting the derivative equal to 0 leads to the ML estimate of $\mathbf{v}$ denoted $\widehat{\mathbf{v}}$.

$$
\widehat{\mathbf{v}}=\mathbf{A}^{\dagger}(\Omega) \mathbf{x}
$$

where $\mathbf{A}^{\dagger}(\Omega)$ is the pseudo-inverse of $\mathbf{A}(\Omega)$ i.e.

$$
\mathbf{A}^{\dagger}(\Omega)=\left(\mathbf{A}^{T}(\Omega) \mathbf{A}(\Omega)\right)^{-1} \mathbf{A}^{T}(\Omega)
$$

and where $(.)^{-1}$ corresponds to the matrix inverse.

The ML estimate of $\Omega$ is obtained by minimizing $\mathscr{L}(\mathbf{x} ; \widehat{\mathbf{v}}, \Omega)$ with respect to $\Omega$. By replacing $\mathbf{v}$ by $\widehat{\mathbf{v}}$ in (8), we obtain

$$
\{\widehat{\Omega}\}=\arg \max _{\Omega} \mathscr{J}(\Omega)
$$

where:

$$
\mathscr{J}(\Omega)=\mathbf{x}^{T} \mathbf{A}(\Omega) \mathbf{A}^{\dagger}(\Omega) \mathbf{x}
$$

2) Estimate of model order L: In order to extend the MLE for model order estimation $\widehat{L}$, a penalty term based on MDL principle is applied to the MLE cost function in (12). Hence, the estimation of $L$ can be performed by maximizing the penalized ML estimate of $\Omega$ as follows

$$
\begin{aligned}
&\{\widehat{\Omega}, \widehat{L}\}=\arg \min _{\Omega, L}\left(-2 \log p\left(\mathbf{x}, \widehat{\mathbf{v}}, \widehat{\sigma}^{2}, \Omega, L\right)\right. \\
&+c(g, N))
\end{aligned}
$$

where $c(g, N)$ is a penalty function which depends on the number of free parameters $g$ and the number of data samples $N$. Under the assumption that the number of the components is equal to $2 L+1, g=4 L+5$. The criterion information rule used within this paper is the minimum description length (also called the Bayesian Information Criterion Rule) [16] and is given by

$$
c(g, N)=g \log (N)
$$

A straightforward computation leads to following cost function:

$$
\begin{aligned}
\{\widehat{\Omega}, \widehat{L}\}=\arg \max _{\Omega, L}-\left(\mathbf{x}^{T} \mathbf{x}-\mathscr{J}(\Omega)\right) & \\
& \times \exp \left(\frac{c(g, N)}{N}\right)
\end{aligned}
$$

Finally, the PSD estimate of the stator current is composed of two steps: a) the estimates of $\Omega$, and $L$ are obtained from (15), and $b$ ) the vector $\mathbf{v}$ containing the amplitude and the phase of the fault characteristic frequencies is estimated by replacing $\Omega$, and $L$ with its estimates in (9).

About the implementation, the main difficulty relies on the optimization problem in (15). As the maximum can not be found analytically, numerical method should be used to estimate $\Omega$ and $L$. In our context, the cost function is only composed of three parameters $\left(f_{s}, f_{c}\right.$, and $\left.L\right)$, which implies a maximization in a 3-D space. The search space is relatively limited since the variation range of $\Omega$ and $L$ are approximately known. For these reasons, we propose to perform the maximization of (15) with a simple grid-search algorithm [18]. It should be noted that the maximization step could be computationally demanding since it requires the construction and the inversion of a large matrix for each vertex of the grid.

\section{B. Fault Detection Criterion}

In order to successfully perform fault detection, a fault criterion is needed to measure the machine state. As the information about the fault severity is carried out by $a_{k}$ $(k \neq 0)$, we propose to compute the sum of the squares of the (normalized) amplitude of the fault characteristic frequencies. This criterion is expressed mathematically as

$$
\mathscr{C}=\sum_{k=-L, k \neq 0}^{L}\left(\frac{a_{k}^{2}}{a_{0}^{2}}\right)
$$

The proposed criterion in (16) depends on the amplitudes $a_{k}(k=-L, \cdots, L)$. Once the PSD is estimated, $a_{k}$ can be extracted from the vector $\widehat{\mathbf{v}}$. This fault detection criterion is an extension of the total harmonic distortion (THD) [19].

The fault detection algorithm is summed up in Fig. 2. This algorithm can be implemented for real-time monitoring of an induction machine. Compared to other PSD-based monitoring technique (Periodogram, MUSIC, ESPRIT), the proposed approach is quite attractive since the vector $\mathbf{v}$ directly conveys information about the characteristic frequencies.

\section{APPLICATION TO INDUCTION MACHINE FAULTS DETECTION}

The proposed approach has been implemented in MatlabSimulink $^{\circledR}$ on a HP ProBook PC at $2.2 \mathrm{Ghz}$ with 2 Go of RAM. Its performance is evaluated with simulated stator currents for eccentricity and broken rotor bars faults and experimental data for bearing failures. 


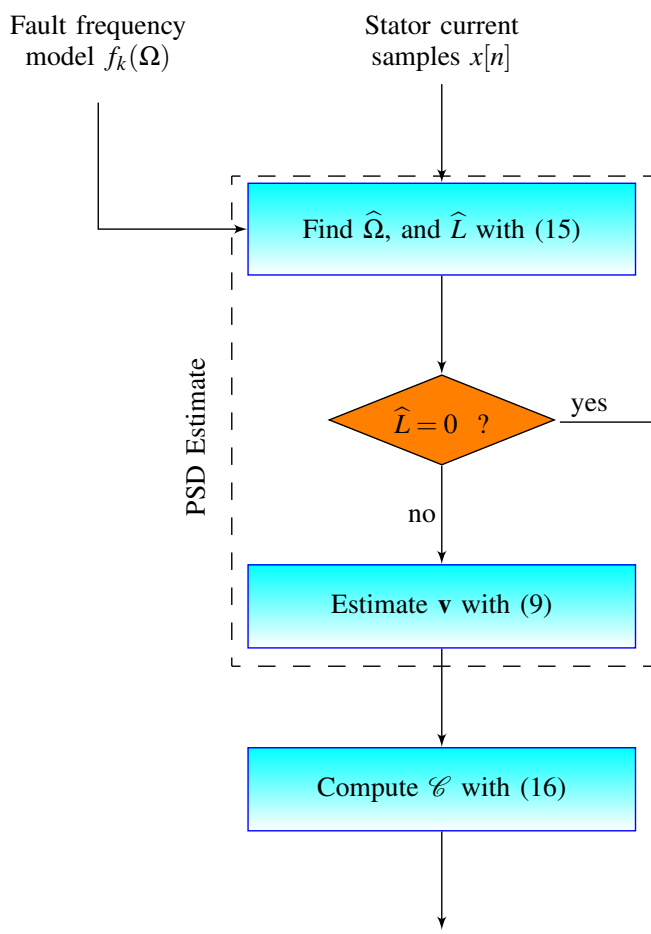

Fault severity/Decision
No fault

Fig. 2. Fault detection algorithm.

\section{A. Simulation Results}

An induction machine model for healthy and faulty machines has been developed based on the coupled magnetic circuits theory [5], [20], [21]. In these simulations dynamic eccentricities are introduced to emulate a bearing fault. Indeed, a bearing fault will cause a mechanical vibration, essentially equivalent to a dynamic eccentricity [22], [23]. In the carriedout simulations, bearing faults are emulated by generating rotating eccentricities at bearing characteristic fault frequency $f_{c}$ which leads to periodical changes in the induction machine inductances [23]. Moreover, broken rotor bars are emulated by suppressing the corresponding broken rotor bar.

1) Eccentricity fault detection results: The algorithm shown in Fig. 2 is used to extract a fault detection criterion. The eccentricity fault characteristic frequency is used, i.e. $f_{k}(\Omega)=f_{s} \pm k f_{c}$ where $f_{c}=\left(\frac{1-s}{p}\right) f_{s}$. The grid search algorithm has been implemented using a fine search: $f_{c}$ ranges from $0 \mathrm{~Hz}$ to $100 \mathrm{~Hz}$ with a step size of $0.01 \mathrm{~Hz}$. Table 2 summarizes the simulation results. This table presents the estimated fault frequency $f_{c}$, the sidebands number $L$, and the fault detection criterion $\mathscr{C}$.

The analysis of Table 2 allows concluding that the proposed approach permits to detect the eccentricity fault. Indeed in presence of eccentricity faults, the fault criterion increases significantly. Therefore, a simple threshold-based decision can distinguish between the healthy and the faulty cases.
Table 2. Eccentricity fault simulation results.

\begin{tabular}{|c||c|c|c|}
\hline State & $\begin{array}{c}\widehat{L} \\
(\mathrm{~Hz})\end{array}$ & $\begin{array}{c}\widehat{f}_{c} \\
(\mathrm{~Hz})\end{array}$ & $\begin{array}{c}\mathscr{C} \\
\left(\times 10^{-3}\right)\end{array}$ \\
\hline Healthy & 0 & 0 & 0 \\
\hline $\begin{array}{c}\text { Static } \\
\text { eccentricity }\end{array}$ & 1 & 24.46 & 1.1 \\
\hline $\begin{array}{c}\text { Dynamic } \\
\text { eccentricity }\end{array}$ & 1 & 48.87 & 5.3 \\
\hline $\begin{array}{c}\text { Mixed } \\
\text { eccentricity }\end{array}$ & 2 & 24.43 & 8 \\
\hline
\end{tabular}

2) Broken rotor bars fault detection results: Broken rotor bar is one of the electrical faults that is difficult to detect since the squirrel cage current can not be acquired. The broken rotor bars characteristic frequency is used in the signal model i.e. $f_{k}(\Omega)=f_{k}\left(f_{s}, s\right)=f_{s}\left[k\left(\frac{1-s}{p}\right) \pm s\right]$. Computer simulations have been performed for assessment of operating features of the proposed fault detection scheme.

Table 3. Broken rotor bars simulation results.

\begin{tabular}{|c||c|c|c|}
\hline State & $\widehat{k / p}$ & $\begin{array}{c}\widehat{s} \\
(\%)\end{array}$ & $\begin{array}{c}\mathscr{C} \\
\left(\times 10^{-3}\right)\end{array}$ \\
\hline Healthy & 0 & 0 & 0 \\
\hline 1 broken bar & $1,3,5$ & 5.8 & 4.6 \\
\hline 2 broken bars & $1,3,5,7$ & 6.2 & 24.4 \\
\hline 3 broken bars & $1,3,5,7$ & 6.6 & 49.7 \\
\hline
\end{tabular}

Table 3 gives simulation results for 1 to 3 broken rotor bars for the proposed parametric estimation technique. The broken bars are adjacent. The criterion has been evaluated for different fault degrees. It can be noticed that the fault criterion varies in proportion to the number of broken rotor bars. It is worthy to notice that in the proposed approach case, the estimation of $\frac{k}{p}$ leads to informations about faults presence. Furthermore, It permits to enhance the sensitivity of the fault criterion.

\section{B. Experimental Results}

Bearing failure is one of the foremost causes of breakdowns in rotating machinery, resulting in costly downtime [17]. One of the key issues in bearing prognostics is to detect the defect at its incipient stage and alert the operator before it develops into catastrophic failure.

1) Test rig: A conventional $0.75 \mathrm{~kW}$ induction machine drive test rig is used in order to test the proposed parametric spectral estimation fault detection approach [1].

The test rig mechanical part (Fig. 3) is composed by a synchronous and an induction machine. The induction machine is fed by the synchronous generator in order to eliminate time harmonics. Indeed, this will automatically eliminate supply harmonics and therefore allow focusing only on bearing faults 
effect on the stator current. The induction machine rated parameters are given by Appendix A.

The induction machine has two 6204.2 ZR type bearings (single row and deep groove ball bearings) with the following parameters: outside diameter is $47 \mathrm{~mm}$, inside diameter is 20 $\mathrm{mm}$, and pitch diameter $\mathrm{D}$ is $31.85 \mathrm{~mm}$. A bearing has 8 balls with an approximate diameter $\mathrm{d}$ of $12 \mathrm{~mm}$ and a contact angle of $0^{\circ}$. Bearing faults are obtained by simply drilling holes in different parts [24]. In order to study the load influence, the induction machine was operated with various load levels ranging from $0 \mathrm{~W}$ to $400 \mathrm{~W}$.

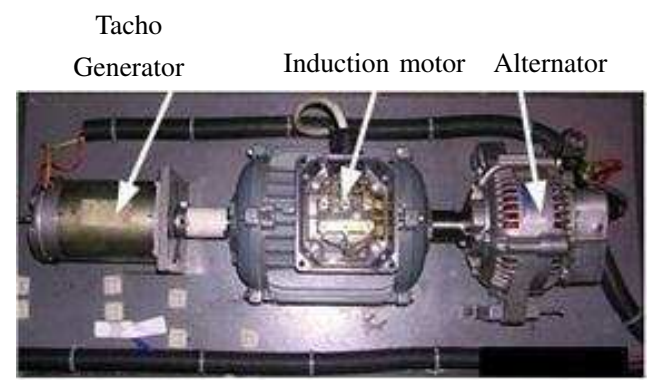

(a) Mechanical part.

\section{Connectors to}

the mechanical part Current transformers Load(bulbs)

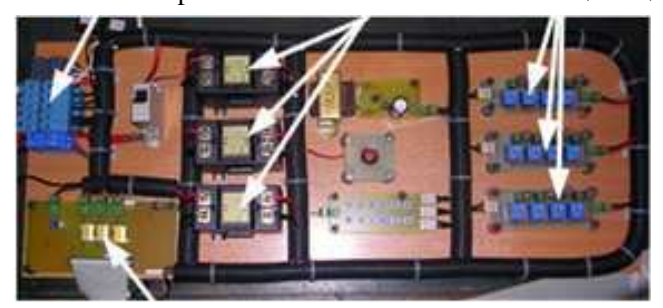

Outlet to DAQ

card and PC

(b) Electrical part.

Fig. 3. Test rig.

The measured quantities for off-line bearing fault detection were the line-currents. For all the experiments, the stator fundamental frequency was equal to $f_{s}=50 \mathrm{~Hz}$. All the signals were acquired at a $10 \mathrm{kHz}$ sampling frequency by a data acquisition card and processed using Matlab-simulink ${ }^{\circledR}$. As the information relative to the bearing faults is mostly located below $300 \mathrm{~Hz}$, these signals were down-sampled at a $600 \mathrm{~Hz}$ sampling rate.

2) Fault detection results: In presence of bearing faults, it has been shown in [23], [25] that the fault characteristic frequencies are given by: $f_{k}(\Omega)=\left|f_{s} \pm k f_{c}\right|(k \in \mathbb{Z})$. The algorithm in Fig. 2 is again used to extract a fault detection criterion. Similarly to the simulation configuration, the number $L$ has been estimated in order to decide whether the induction machine is operating with healthy bearings or damaged ones. If $L=0$ then the bearings are safe, otherwise the bearing is damaged and criterion in (16) is computed in

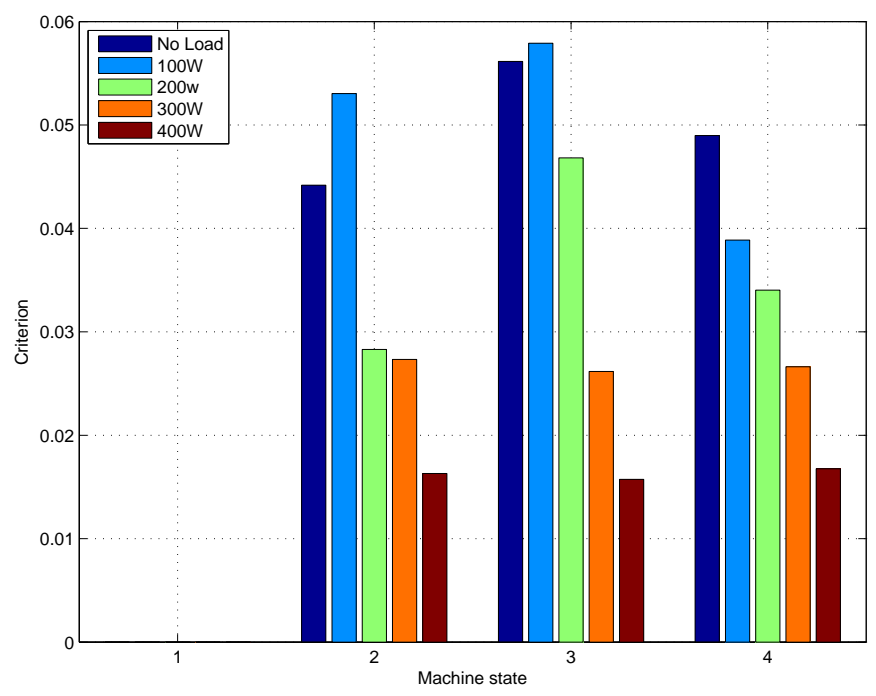

Fig. 4. Proposed approach: values of the fault detection criterion $\mathscr{C}$ for 1- Healthy case 2- Inner raceway fault 3- Cage fault 4- Ball fault.

order to measure the fault severity and then take decision. Preliminary tests have shown that most of the characteristic fault frequencies are greater than $f_{s}=50 \mathrm{~Hz}$ (for example $f_{c}=66.6 \mathrm{~Hz}$ for ball defect) which means that most of the frequency components related to fault are located at the rightside of the supply frequency $f_{s}$ due to the absolute value of the frequencies introduced by faults (Table 1). Therefore, the proposed approach has been used to extract these rightside components. This simplification is not equivalent to minimization of time harmonics in power supply since these frequencies are different from multiples of the fundamental frequency $f_{s}=50 \mathrm{~Hz}$.

Experimental results are reported in Fig. 4 for the proposed method. This figure displays the criterion $\mathscr{C}$ for healthy and faulty machines with various load levels.

For the proposed fault detection approach, in the case of healthy machine, the model order estimate $\widehat{L}$ is zero which implies that the criterion is equal to 0. From this bar chart, it could be observed that the proposed criterion significantly increases for each faulty machine, regardless of the fault type and load level. Therefore, a simple estimation of $L$ gives an indication of the existence of fault. To determine fault severity, the proposed criterion computation is mandatory and threshold-based fault detector must be defined.

This figure also shows that the criterion $\mathscr{C}$ decreases with the load level. This could be explained by the fact that the load tends to hide the faults effect on the stator current. However, the fault severity criterion remains clearly higher than in the case of healthy machine. These results confirm the effectiveness of the proposed technique for bearing faults detection.

\section{CONCLUSION}

This paper has proposed a statistical-based approach for fault detection in induction machines. The proposed PSD 
estimator has been computed using the maximum likelihood estimation approach. As opposed to non-parametric PSD estimators, the proposed technique exploits the fault frequency signatures in order to improve the performance of the fault detection criterion. As a result, the proposed estimator has better frequency-resolution and frequency-accuracy than other techniques such as the periodogram.

The proposed approach was successfully tested on simulations (eccentricity and broken rotor bars) and experimental tests with various bearing faults and load conditions. Simulation and experimental results have corroborated the efficiency of the proposed method, regardless of the fault type. Furthermore, these results have suggested that the estimation of $L$ is very interesting since it allows to make a direct and fast first idea about the machine operating state.

\section{APPENDIX A}

RATED DATA OF THE TESTED INDUCTION MACHINE

$0.75 \mathrm{~kW}, 50 \mathrm{~Hz}, 220 / 380 \mathrm{~V}, 3.4 / 1.95 \mathrm{~A}, 2780 \mathrm{rpm}, p=1$

\section{ACKNOWLEDGMENT}

The financial support provided by Brest Métropole Océane (BMO) is gratefully acknowledged.

\section{REFERENCES}

[1] E. H. El Bouchikhi, V. Choqueuse, and M. E. H. Benbouzid, "Current frequency spectral subtraction and its contribution to induction machines' bearings condition monitoring," IEEE Trans. on Energy Conversion, vol. 28, no. 1, pp. 135-144, March 2013.

[2] V. Choqueuse, M. E. H. Benbouzid, Y. Amirat, and S. Turri, "Diagnosis of three-phase electrical machines using multidimensional demodulation techniques," IEEE Transactions on Industrial Electronics, vol. 59, no. 4, pp. 2014-2023, April 2011.

[3] A. Bellini, F. Filippetti, C. Tassoni, and G. A. Capolino, "Advances in Diagnostic Techniques for Induction Machines," IEEE Transactions on Industrial Electronics, vol. 55, no. 12, pp. 4109-4126, December 2008.

[4] M. E. H. Benbouzid, "A review of induction motors signature analysis as a medium for faults detection," IEEE Transactions Industrial Elec tronics, vol. 47, no. 5, pp. 984-993, October 2000.

[5] E. H. El Bouchikhi, V. Choqueuse, M. E. H. Benbouzid, J. Charpentier, and G. Barakat, "A comparative study of time-frequency representations for fault detection in wind turbine," in Proceedings of the 2011 IEEE IECON, Melbourne (Australia), November 2011, pp. 3584-3589.

[6] A. Bellini, A. Yazidi, F. Filippetti, C. Rossi, and G. Capolino, "High frequency resolution techniques for rotor fault detection of induction machines," IEEE Transactions on Industrial Electronics, vol. 55, no. 12, pp. 4200-4209, December 2008.

[7] A. Yazidi, H. Henao, G. A. Capolino, M. Artioli, and F. Filippetti, "Improvement of frequency resolution for three-phase induction machine fault diagnosis," in Proc. 40th IAS Annual Meeting Conference Record of the 2005, Hong Kong, China, October 2005, pp. 20-25.
[8] P. Stoica and R. Moses, Introduction to Spectral Analysis. Prentice Hall, 1997.

[9] Z. Leonowicz, T. Lobos, and J. Rezmer, "Advanced spectrum estimation methods for signal analysis in power electronics," IEEE Transactions on Industrial Electronics, vol. 50, no. 3, pp. 514-519, June 2003.

[10] J. Stack, T. Habetler, and R. Harley, "Bearing fault detection via autoregressive stator current modeling," IEEE Transactions on Industry Applications, vol. 40, no. 3, pp. 740-747, May/June 2004.

[11] Y. Kim, Y.and Youn, Hwang, D. Sun, and D. J.; Kang, "High-resolution parameter estimation method to identify broken rotor bar faults in induction motors," IEEE Transactions on Industrial Electronics, vol. 60, no. 9, pp. 4103 - 4117, September 2013.

[12] A. Bracale, G. Carpinelli, L. Piegari, and P. Tricoli, "A high resolution method for on line diagnosis of induction motors faults," in Proceedings of IEEE Power Tech., Lausanne, Suisse, July 2007, pp. 994-998.

[13] S. H. Kia, H. Henao, and G. A. Capolino, "A high-resolution frequency estimation method for three-phase induction machine fault detection," IEEE Transactions on Industrial Electronics, vol. 54, no. 4, pp. 23052314, August 2007.

[14] A. Garcia-Perez, R. de Jesus Romero-Troncoso, E. Cabal-Yepez, and R. Osornio-Rios, "The application of high-resolution spectral analysis for identifying multiple combined faults in induction motors," IEEE Transactions on Industrial Electronics, vol. 58, no. 5, pp. 2002-2010, May 2011.

[15] S. M. Kay, Modern Spectral Estimation: Theory and Application. Prentice Hall, Englewood Cliffs, New Jersey, 1988.

[16] P. Stoica and Y. Seln, "A review of information criterion rules," IEEE Signal Processing Magazine, vol. 21, no. 4, pp. 36-47, July 2004.

[17] A. H. Bonnett and C. Yung, "Increased efficiency versus increased reliability," IEEE Industry Applications Magazine, vol. 14, no. 1, January/February 2008.

[18] S. Kay, Fundamentals of Statistical Signal Processing: Estimation Theory. Prentice-Hall signal processing series, 1993, 17th Printing.

[19] A. E. Emanuel, "Summary of ieee standard 1459: definitions for the measurement of electric power quantities under sinusoidal, nonsinusoidal, balanced, or unbalanced conditions," Industry Applications, IEEE Transactions on, vol. 40, no. 3, pp. 869-876, 2004.

[20] A. Ceban, R. Pusca, and R. Romary, "Study of rotor faults in induction motors using external magnetic field analysis," IEEE Transactions on Industrial Electronics, vol. 59, no. 5, pp. 2082-2096, May 2012.

[21] D. Dupont and A. Gautriaud, "Failure modeling in wind and tidal turbine generators: development of simulation tool," University of Brest, Tech. Rep., November 2011.

[22] A. Knight and S. Bertani, "Mechanical fault detection in a medium-sized induction motor using stator current monitoring," IEEE Transactions Energy Conversion, vol. 29, no. 4, pp. 753-760, December 2005.

[23] R. Schoen, T. Habetler, F. Kamran, and R. Bartheld, "Motor bearing damage detection using stator current monitoring," IEEE Transactions on Industry Applications, vol. 31, no. 5, pp. 1274-1279, November/December 1995.

[24] Z. Obeid, S. Poignant, J. Regnier, and P. Maussion, "Stator current based indicators for bearing fault detection in synchronous machine by statistical frequency selection," in Proceedings of the 2011 IEEE IECON 2011, Melbourne, Australia, November 2011, pp. 2036-2041.

[25] M. Blodt, P. Granjon, B. Raison, and G. Rostaing, "Models for bearing damage detection in induction motors using stator current monitoring," IEEE Transactions on Industrial Electronics, vol. 55, no. 4, pp. 18131822, April 2008. 